\title{
Quality Living Environment: a Public or Private a Matter
}

\author{
Agnė Ivanauskaité
}

Vilnius Gediminas Technical University, Faculty of Architecture, Department of Urban Design, Pylimo g. 26/1, LT10223, Vilnius, Lithuania

\begin{abstract}
Nowadays, one of the most important questions is the quality of living environment. The development of quality living environment deals with a conflict between publicity and privacy: who is responsible for creating quality living environment, where is the line between publicity and privacy, how the balance between publicity and privacy should be achieved? The article discusses modern-day issues and different opinions about publicity - privacy, from a viewpoint of creating quality living environment. The author accentuates the significance of community and role of individual in forming a quality living environment in contemporary world.
\end{abstract}

Keywords: Community, living environment, private, public, society, space.

\section{INTRODUCTION}

"The responsibility of a group for its territory includes the well functioning of other living things in that place, just as much as a care for its continued human usefulness. Residents may be brought to account by trust for the demise of a marsh, for example, as well as by regional government for injury to a neighbor. They can be required to maintain or replenish the soil, or the water table, or a stand of trees. People and land belong to each other. In the early days, residents might so misuse their land as to be dispossessed on that account, but it is the nonresidential lands that have proved to be the more enduring problem. Maintenance can more easily be brought to a formal standard there, but it is not so easy to foster an attitude of caring [1]."

For most of us our living environment ends at a doorsill of our homes; we do not have to look very hard to notice the general indifference to those surrounding spaces that seemingly do not belong to us. Aiming for personal benefit, ravaging the environment, making decisions without regard to the interest of society - these are the stories that often flash in media. In order to preserve social, economic and ecological balance we often call for implementing sustainable development and prioritizing the importance of community in contemporary cities. However, asked to define the difference between what is public and what is private, we often find ourselves confused. Is not it surprising, especially having in mind that the origin of humanity is in fact communities?

*Address correspondence to this author at the Vilnius Gediminas Technical University, Faculty of Architecture, Department of Urban Design, Pylimo g. 26/1, LT - 10223, Vilnius, Lithuania; Tel: + 370618 82300;

Fax: +370 5270 0112; E-mail: agne.ivanauskaite@vgtu.lt

\section{MATERIALS AND METHODS}

The goal of this article is to emphasize the need of balance between publicity and privacy as well as the importance of the community and ourselves as individuals in forming a quality-based living environment. The tasks of the article are as follows: to review the concepts of publicity and privacy through history; to introduce the points of conflict between publicity and privacy; to determine the influence of conflict between publicity and privacy on quality living environment; to estimate the need of balance between publicity and privacy during the formation of quality-based living environment; to identify the role of community and individual in creating a quality-based living environment. The article refers to nonfiction literature, legal documents and natural observations.

In the first part of article the author reviews the base and the concept of community, also identifies the source on which the conflict between publicity and privacy is based. The second part of the article is focused on the various perceptions of publicity and privacy. In the third part the private ownership, its legal regulations and problems are analyzed. And the fourth segment of the article discusses the distinct levels of conflict between publicity and privacy, in the end suggesting the appropriate tools for solving the conflict. The entire article deals with the question of how publicity, privacy and the conflict between them influence the quality of our living environment.

\section{PUBLICITY AND PRIVACY THROUGH HISTORY}

The primitive band societies that formed in the lower Palaeolithic era are widely considered to mark the beginning of communal living. Simply put, a community is a group of people who share the sense of belonging and have a common 


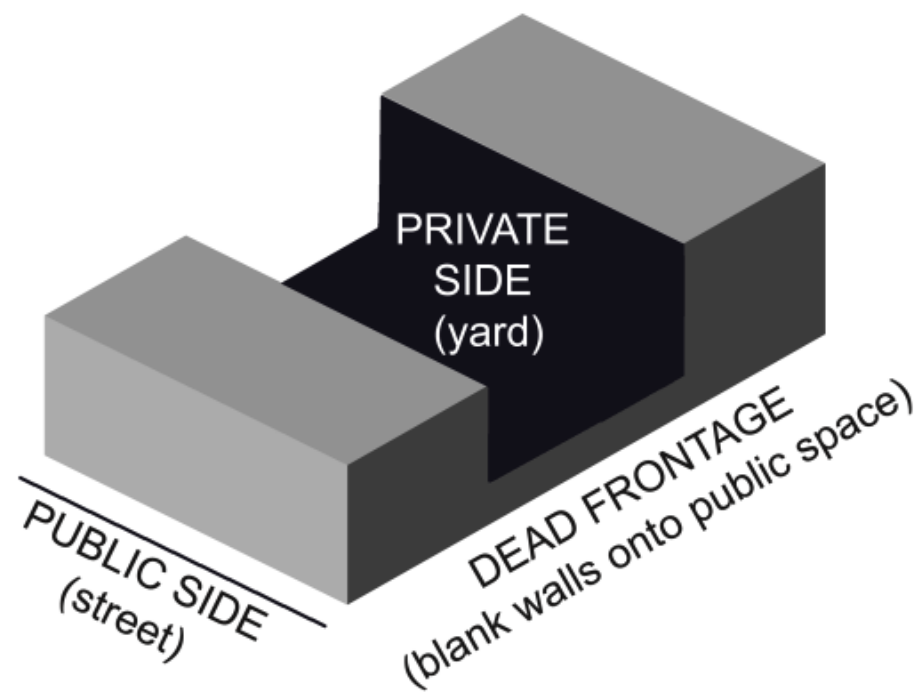

Fig. (1). Scheme of structure organized according to the public - private line.

goal. It can also be compared to an organization, i.e. an alliance of people with common goals. Obviously neither communities nor organizations can exist without a unifying purpose that connects the individuals. However, the importance of a person's individual needs was already discussed in Ancient Greece and later during the Medieval times. Nowadays globalization driven societies cannot avoid social, cultural as well as economic changes. According to an Australian architect William John Mitchell [2] and Polish sociologist Zygmunt Bauman [3], traditional territorial communities are being gradually replaced by non-territorial communities, where people are connected by the same or similar variety of interests. It must be noticed that such segmentation leads us towards the increased amount of communities which determines the significance of growing private interests.

In various historical periods publicity and privacy were defined and perceived differently. Identifying architectural objects as private or public at the same time allows us to establish the addressee. These categories emerged for a reason to diversely define different objects according to customer or undertaker, the audience to which the object will have a direct impact the presumable lawlessness of an artist and other factors [4]. Public and private architectural functions were comprehended differently during each century. For example, up until a few last centuries religious buildings were considered to be more private than public objects. Changing society, the shifting level of knowledge and needs as well as a multitude of other factors influenced the evolution of public and private secular architecture. However, it seems that nowadays categories of publicity and privacy are not sufficient to define an architectural object. The publicity and privacy of objects now must be better researched by creating new categories that first of all would define the objects themselves.

More broadly, in recent centuries the city was divided into public and private spaces. In the Middle Ages first private buildings belonged to the people of the highest social status. From the Middle Ages until the modern times the relationships, links, hierarchical structures changed a lot, also the continuously developing environment had an impact on the growth of the private sector. The Industrial revolution, industrialization and other transformations also weighted in. However, there always existed some room to subtly manoeuvre between publicity and privacy. The discussions that humanity is entering a new era were ignited by the changes that occurred during the XX century, which was formed by improving technologies, growing ecological concerns as well as perpetually changing economic climate. Consequently the urban areas were absorbed by an uncontrollable expansion and a desire for private space lead to the further development of suburban areas. So one of the most important questions now is how to balance public and private spaces in order to sustain viable cities? After all, urban structures are organized according to a line of what is public and what is private (Fig. 1).

\section{DIFFERENT PERCEPTIONS OF PUBLICITY AND PRIVACY}

Different cultures and countries employ a diverse perception of publicity and privacy. For example, the Hindus claim that there is no higher state than a human spirit and it should not depend on public and tangible surrounding. The Confucianists believe the opposite - a human progress can only be measured by successful relations with other people and his connection to the environment [5]. Anthropologist and philosopher Luis Dumont [6] separated traditional non-western cultures into two groups: the ones, where a human is an empirical material in society, and the remaining cultures, where people live according to the collective model and do not recognize freedom or equality as values. It is frequently stated that modern Western culture liberated human from the clutches of society [5]. Each individual gained a right to a private ownership, could enjoy freedom and equality regardless of his social status. Accordingly, the expansion of private ownership was further encouraged. However, one of the reasons of giving equal rights to all was to let people work for communities and to create the innovations in various fields. 
The disjuncture between public and private spaces is related to natural human needs. Anthropologist Edward Twitchell Hall [7] characterizes four categories of space that humans are able to perceive: intimate, personal, social and public. Social and public spaces are at a similar level, however public space is not as easily controlled. Our personal space is the one that surrounds the human body. It may be defined as a social institution that depends on a personal social status, a particular phase of life, the environment and other factors. People frequently need to adapt to changing circumstances, therefore their personal space also constantly changes. Intimate and personal spaces cannot be defined by law, but the advancing technologies provide a better chance to protect these venerable spaces as well as increase their importance. For example, a person driving a car can easily determine his personal space. It can also be argued that the internet protects personal space by preventing direct contact. However, similar phenomenons simply promote our desire to be alone, interfere with the customary social life and push people away from public city spaces.

In theory, there are several diverse opinions on the need of privacy. Political theorist Hannah Arendt claims that a person does not exist privately because each human is linked to the environment and influences other people [8]. Conversely, K. Marx and F. Engels give the most attention to personal privacy [9]. Furthermore, law and philosophy professor Jeremy Waldron [10] identifies more problems in discussion about personal privacy. He sneers at human right to private ownership as an expression of freedom and equality. Jeremy Waldron raises a question: is there a point to discuss privacy and equality when there are so many homeless people and so many others, who have a higher social status, but are not willing to help their community in order to protect their privacy? Despite various opinions, there is a clear consensus of the need to ensure a balance between publicity and privacy. The conflict arises only when we must decide where to draw the fine margin between publicity and privacy; otherwise it would be impossible to distinguish the two.

\section{PRIVATE OWNERSHIP}

A private domain can be described as the one controlled by individual and inapproachable to public observation or knowledge. Although private space is usually supervised by a particular person, it often falls into public sector as well. A good example would be a private workspace in a public library. The method of separating a private space was already applied in Ancient Greece. The residential houses were surrounded by the so called no-one's land that could be entered by anyone, but nobody had a right to touch a house that was not your own [8]. During the Middle Ages agricultural fields were regarded in a similar fashion: these territories were also surrounded by the no-one's land to avoid any possible damage that would potentially harm the neighbours estate. Such practices illiterate the need to restrict different territories as much as possible in order to avoid chaos. This means there must be no unrestricted territories. However, it is also imperative for the territories and spaces to be flexible - solely for the purpose of not encouraging the aspiration to seek unlimited power. Cultural, physical and social needs of individuals must be protected from invasion of outsiders. As well as this, communities must also be insulated from harmful, selfish and publicly disadvantageous activities of individuals.

The privacy traditionally is associated with private land ownership. However, the need for private ownership was considered to be controversial even in Ancient times. Plato believed owning land motivates people to pursuit wealth. This is especially true to the functionaries who are in position to seek personal prosperity without considering the interests of community [9]. However, Aristotle [11] argued that private ownership provides freedom and also that it is possible to conjunct public and private interests. Aristotle claimed that the more owners there were, the less respect for the property existed. On the other hand, the land becomes worthless if people do not contribute to it. Therefore a bigger quantity of owners or at least a bigger contribution towards the particular territories can be very beneficial. It should not be considered as an invasion to another's property, because it is simply a particular tool to promote people's mentality and cultural training.

As stated, private ownership might give people a certain freedom, but is there a way to control the owners? A land requires to be maintained thoughtfully in economical, ecological, aesthetically and other aspects (Fig. 2). In the United States of America the privacy is viewed as someone's ability to choose their own way of life; however, in order to guarantee the well-being of the society, some exceptions (regulated restraints) might occur. In Great Britain the protection of privacy is guaranteed by law. Nonetheless, in different societies and countries, the impacts and the perception of how the privacy must be regulated is not the same.

In Lithuania the private ownership management practice faces many issues. In the beginning of the land reform (1990) it was processed methodologically, but starting 1995 the step-by-step processes continued to be neglected. Territorial planning became chaotic and dependent on interests of land owners after they were given more rights and the control of land use was reduced [12]. The current Lithuanian legal framework has no land use policies or regulations that would define the law of ownership and would control the quality of the environment that is being formed by ensuring the public interest.

In Lithuanian language public interest is a clear combination of words, but it is not determined by law in the domain of territorial planning. Without an explicit legal definition, public interest in territorial planning stays unclear. Furthermore, this situation makes it impossible to evaluate what kind of decisions would properly represent the public interest [13]. First of all, it is necessary to establish what society needs to know how much it can interfere with cities development. Also it is very important to identify, define and offer solutions for the situations when a public interest contradicts a personal interest. When public and personal interests differ, suppression of any side must be replaced by supplying for the needs of both sides. 


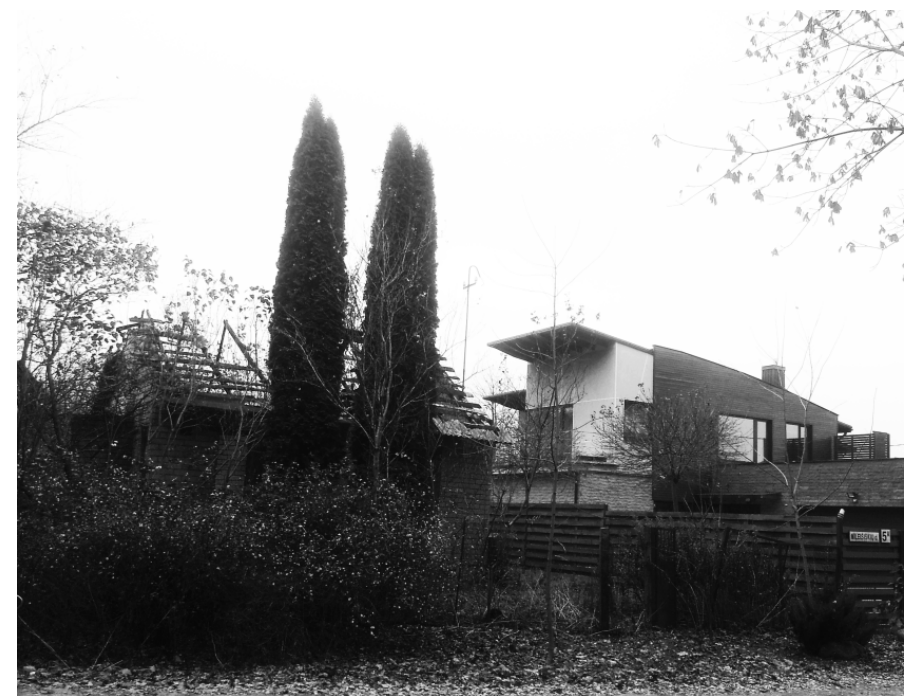

Fig. (2). Abandoned house - uncontrolled private territory.

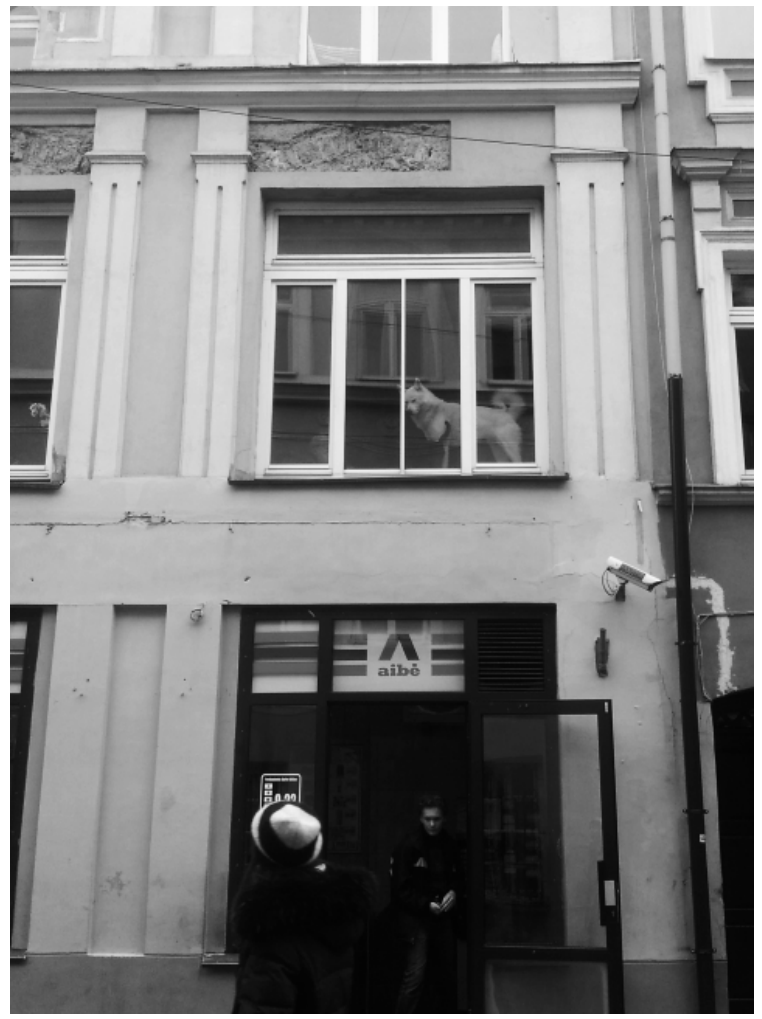

Fig. (3). The first level of conflict between public and private interests - private property in relation with public.

\section{CONFLICT BETWEEN PUBLIC AND PRIVATE IN- TERESTS}

The benefit for society and the benefit for individual should not be considered the same or confused. The conflict between public and private interests is often conditioned by modifications of definitions that occur as centuries pass, also by the absence of new definitions in certain fields, the lack of resolve in how and where the boundary must be drawn, as well as how to balance these categories with other factors. Ali Madanipour [9], a professor of urban planning, distinguishes three levels of conflict. The first one involves a home - a place that leaves the least room for discussions of what is private and public, because it is owned privately (Fig. 3). However, is must be said that at this level it is almost impossible to control the owners. The middle level encompasses semi-public spaces, for example, schools (Fig. 4). In this level there is no specific owner but there are lots of consumers who spend most of their days in these spaces. Therefore, the users feel responsible to take care of the environment that they spend so much time in. The third level encompasses public spaces that are almost impossible to control (Fig. 5). 


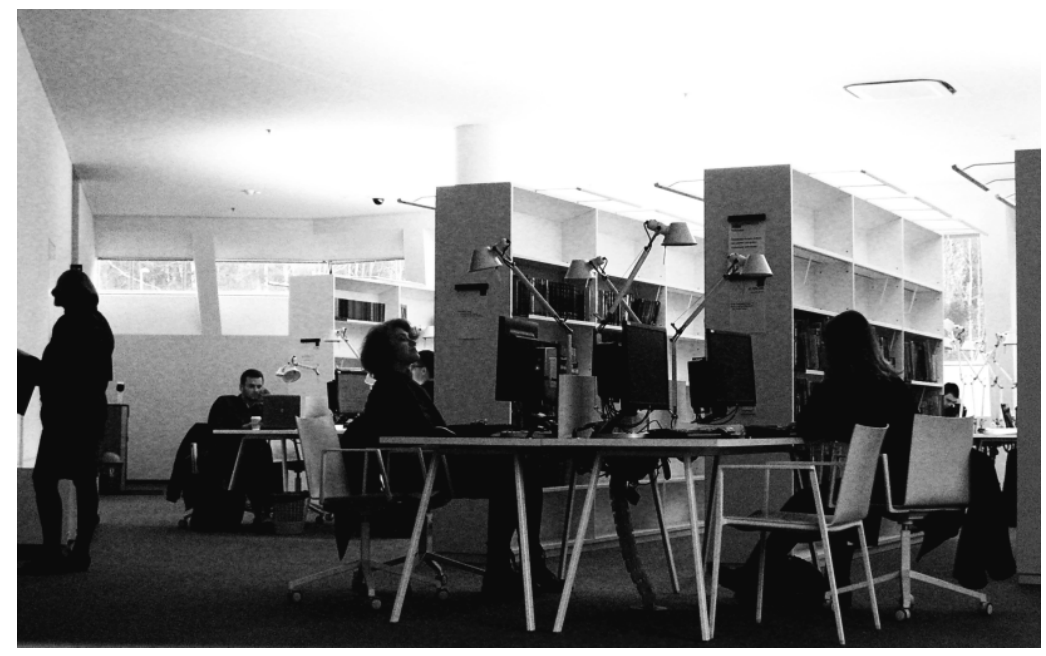

Fig. (4). The middle level of conflict between public and private interests - semi-public space.

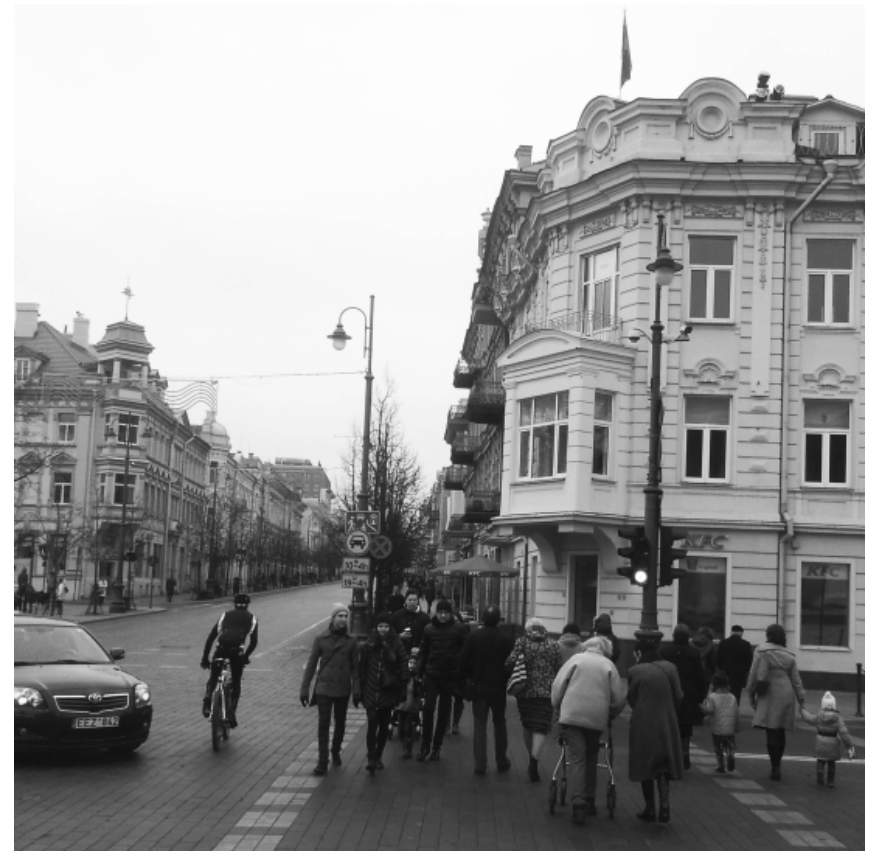

Fig. (5). The third level of conflict between public and private interests - public space which is almost impossible to control.

An uncontrolled space can encounter many problems: violence, vandalism, pollution, etc. It is an unsafe and dangerous environment, it can be perilous, unaesthetic, uncomfortable and even unhygienic. Our living environment is not limited to private property. Public spaces are designed for everyone to use, so the maintenance of these spaces should be done by more people, not just that one particular owner. People should feel responsibility for their living environment. The physical and functional qualities of living environment are very important features of the city structure; they influence various processes, impact our health and integrity of natural and anthropogenic elements.

In the "Habitat" conference in 1976 the United Nations distinguished the quality of life as the ultimate goal in city development [14]. Since then, the quality of cities has been conditioned by various compulsory standards that were based mostly on economic and technological aspects. Later these were supplemented by various hygiene requirements. However up to now no clear factors were formulated to determine the quality of living environment and no tools were provided to improve it. The concept of sustainable development was coined recently and it became an aspirational template of how to improve the quality of living environment.

The concept of sustainable development includes the evolution of society in ecological, social and economic aspects. Sustainable development also targets the protection of private property and public interest, the quality of living environment and the significance of community. But there are no clear directions how to adapt private and public sectors to each other. In the entire world there are only a few cities that 


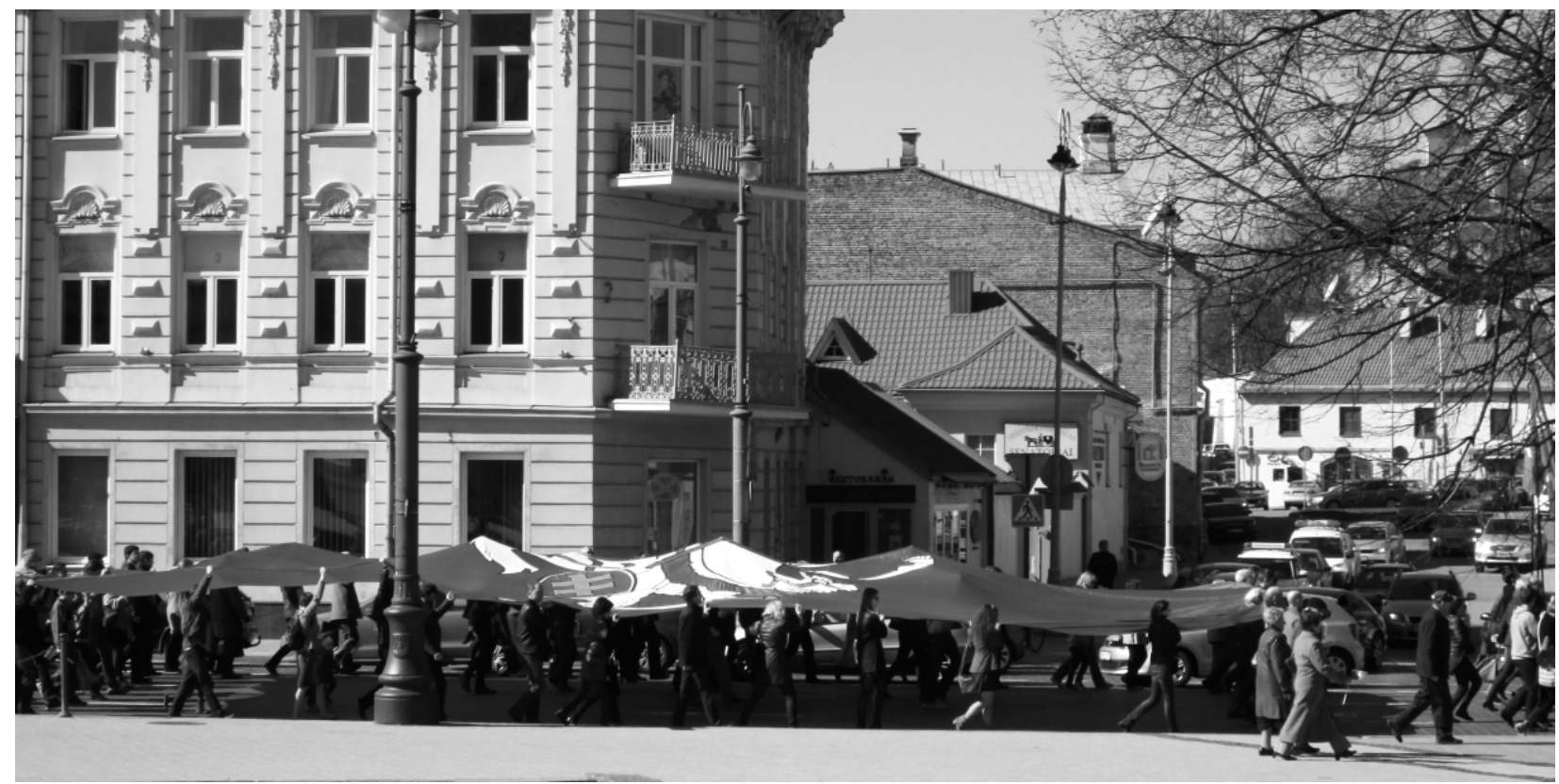

Fig. (6). People are together as a community because of the one common goal - National celebration.

could be nominated as successful examples of sustainable development [15]. Probably one of the biggest issues that prevent the implementation of sustainable development in territorial planning nowadays is the inability to define publicity and privacy. Also, the stagnancy in sustainable development, especially its ecological direction is largely determined by the passive mentality of society and individuals. So, the question arises: what kind of quality of living environment can we discuss, if there are no legally determined waymarks and tools to ensure the development, and if the society itself is in general indifferent to the environment?

Nevertheless, there is no doubt that more attention must be paid to ecology. In some situations, ecological development and a desire to create ecological objects may be seen as a mass phenomenon. There are lots of discussions about ecology as a fashion. Many people tend to buy anything labelled "eco", although it does not mean that the thing they are so eagerly buying is truly ecological. It is not a secret that fashion is a very powerful tool that influences people's lifestyle. If ecology is riding the fashion wave, we should not judge it. Fashion is a tool that may be used to create an ecologically aware community and to inspire individuals to pay more attention in creating ecological environment. Such use of fashion is just an example of how different communities can be formed and an impact that can be made on a person. During the history the most extraordinary examples of individuals coming together for a higher cause, becoming a community, contesting for a public interest are the ones that emphasize the believe in the nation as a unified entity (Fig. 6).

\section{CONCLUSION}

Anyone is dependent on community at all times. Obviously, communities were historically programmed to fragmentise. But now, by aiming to make the quality of living environment the ultimate goal of city development, by revolutionizing the ecology, and moving forward with the practice of sustainable development we prove that communities are necessary the same way as thousands of years ago. Rapid technological advance, gaps in legal basis, conflict between publicity and privacy, digression of individuals from society and a lack of respect for our own living environment impede the advancement of quality living environment.

Modern Western culture was formed with a purpose to make people work for community. Modern-day community needs work as a cyclic law and derogate the importance of human as a private person. This law determines the decrease of private sector, the increase of public sector and the definition of optimum balance between them. However, today there are many tools that widen the gap between individuals and society; people often forget that without personal and communal efforts as well as a healthy amount of need to control the owners, the land loses its value. Consequently, if we will not modify our values scales, if we will not make drastic changes in our legal system as well as education and other sectors, if we will fail to find a balance between publicity and privacy, the living environment will continue to regress.

\section{CONFLICT OF INTEREST}

The author confirms that this article content has no conflict of interest.

\section{ACKNOWLEDGEMENTS}

Declared none. 


\section{REFERENCES}

[1] Lynch K. Good city form. Cambridge, MA: MIT Press 1984.

[2] Mitchell WJ. Placing words: Symbols, Space and the City. Cambridge, MA: MIT Press 2005.

[3] Bauman Z, Eds. Globalizacija: pasekmès žmogui (Globalization: the human consequences). Vilnius: Apostrofa 2007.

[4] Belting H, Dilly H, Kemp W, Sauerländer W, Warnke M, Eds. Meno istorijos ivadas (Introduction to History of Art). Vilnius, Alma littera 2002.

[5] Morris B. Anthropolgy of the Self: The individual in cultural perspective. London: Pluto Press 1994.

[6] Dumont L, Ed. Esė apie individualizmą: modernioji ideologija antropologiniu požiūriu (Essays on Individualism: Modern Ideology in Anthropological Perspective). Vilnius: Baltos lankos 2002.

[7] Hall ET. The Hidden Dimension: Man's use of space in public and private. New York: Anchor Books 1990.
[8] Arendt H, Ed. Žmogaus būklè (The Human Condition). Vilnius: Margi raštai 2005.

[9] Madanipour A. Public and private spaces of the city. London: Routledge 2003.

[10] Waldron J, Ed. Liberal rights: collective papers 1981 - 1991. Cambridge University Press: UK 1993.

[11] Aristotle, Ed. Politika (Politics). Vilnius: Margi raštai 2009

[12] Ramanauskas E. Legal significance of land property for territory planning. Town Planning Archit 2009; 33(2): 82-91.

[13] Staniūnas E. On definitions of public interest in urban development of Lithuania. Town Planning Archit 2008; 32(4): 248-57.

[14] The Vancouver declaration on Human Settlements. From the report of Habitat: United Nations Conference on Human Settlements, Vancouver, Canada, 31 May to 11 June 1976. Retrieved on September 16, 2014. Available from: http://mirror.unhabitat.org/downloads/docs/The Vancouver_Declaration.pdf

[15] Juškevičius P. Quality of life and sustainable development in urban design. Town Planning Archit 2005; XXIX (4): 174-81.

Received: June 10, 2015

Revised: June 15,2015

Accepted: June 15, 2015

(C) Agnè Ivanauskaitė; Licensee Bentham Open.

This is an open access article licensed under the terms of the Creative Commons Attribution-Non-Commercial 4.0 International Public License (CC BY-NC 4.0) (https://creativecommons.org/licenses/by-nc/4.0/legalcode), which permits unrestricted, non-commercial use, distribution and reproduction in any medium, provided the work is properly cited. 